\title{
FREQUENCY OF UNRUPTURED ECTOPIC PREGNANCY IN A TERTIARY CARE HOSPITAL OF HAIL CITY, SAUDI ARABIA
}

\author{
Saadia Rasheed, ${ }^{1}$ Sehar Shahbaz, ${ }^{2}$ Shazia Hammad ${ }^{3}$
}

\begin{abstract}
Aims and Objectives: Determine the frequency of unruptured ectopic pregnancy in a tertiary care hospital of Hail City, Saudi Arabia.

Study Design: It was an observational case series.

Material and Method: A total of 150 cases between $15-44$ years with history of amenorrhea $(6-8$ weeks) and vaginal bleeding with or without lower abdominal pain, positive urine pregnancy test were enrolled in the study while heterotopic pregnancy, ruptured ectopic pregnancy and patients in first trimester with obstetric problem other than ectopic pregnancy were excluded from the study. All these cases were collected from Maternity and Children's hospital Hail, Kingdom of Saudia Arabia during 2011 to 2014.

Results: In our study, 64.67\% $(n=97)$ of the cases were between $15-30$ years of age while $35.33 \%(\mathrm{n}=$ 53) were between $31-44$ years, mean \pm sd was calculated as $26.34 \pm 2.67$ years, frequency of unruptured
\end{abstract}

Rasheed S. ${ }^{1}$

Consultant MCH, Hail City, Saudia Arabia

Shahbaz S. ${ }^{2}$

Department of Obstetrics and Gynaecology

Fatima Memorial Hospital, Lahore

Hammad S. ${ }^{3}$

Resident, Hail General Hospital, Saudia Arabia ectopic pregnancy was recorded in $14 \%$ of the cases. Conclusion: The frequency of un-ruptured ectopic pregnancy is higher and TVS may be used for early detection of this morbidity.

Key Words: Ectopic pregnancy, unruptured, Transvaginal sonography.

\section{Introduction}

Ectopic pregnancy is one of the severe life threatening situations during pregnancy and leads to maternal mortality. ${ }^{1}$ In this pregnancy, a fertilized ovum is implanted outside the uterus and mostly in tubes, while very few cases shown it in other organs e.g. abdomen, ovaries, cervix, spleen, omentum, cessarian section scar, and intramural. ${ }^{2}$

The incidence of this morbidity varies between $0.25 \%$ to $1.13 \%$ in Saudi Arabia. ${ }^{1,3}$ Maternal mortalities regarding pregnancy during first trimester is reported in 4 to $10 \%$ of all pregnancy relating mortalities. ${ }^{4}$

Every women of childbearing age presenting with un-explained abdominal pain other than amenorrhea and vaginal bleeding may be suspected with ectopic pregnancy. 5

The exact etiology is not well documented but Pelvic infections, smoking, previous tubal surgery, genital infections, intra-uterine devices use, and endometriosis are considered as common risk factors. ${ }^{6}$ Women having ectopic pregnancy become symptomatic within 12 weeks of gestation, few cases remain undiagnosed and 
go beyond this gestational age. ${ }^{7}$

During the past decade, the morbidity and mortality have significantly decreased due to effective diagnostic modalities e.g. transvaginal sonography (TVS) ${ }^{8}$ but the rate of early pregnancy mortalities indicated in more than $70 \%$ of the cases. ${ }^{9}$

Usually, urinary test in clinical suspicious cases of ectopic pregnancy is performed and if the test is found positive, patients may be followed through TVS. It can detect gestational sac on early stage of pregnancy i.e. 4 to 6 weeks from LMP. ${ }^{10}$

In our setup, daily, a huge number of women visit Gynaecology Outpatient Department relating to various other gynaecological problems, among them unruptured ectopic pregnancies are also presenting. This review was planned to document the frequency of unruptured ectopic pregnancy which may be helpful to assess the burden of problem and to take measures for prevention of maternal morbidity and mortality ruptured ectopic pregnancy.

\section{Material and Methods}

A total of 150 cases between 15 - 44 years with history of amenorrhea ( $6-8$ weeks) and vaginal bleeding with or without lower abdominal pain, positive urine pregnancy test were enrolled in the study while heterotopic pregnancy, ruptured ectopic pregnancy and patients in first trimester with obstetric problem other than ectopic pregnancy were excluded from the study. All these cases were collected from Maternity and Children's hospital Hail, Kingdom of Saudia Arabia during 2011 to 2014.

A detailed information including patient name, age, gestational age, parity was recorded. Internal examination could facilitate tubal ruptured so it was not routinely performed. Urine for pregnancy test and transvaginal ultrasound was performed in all the patients. All the TVS examination was performed by same consultant radiologist having 5 year post fellowship experience. TVS was done by using $5 \mathrm{MHz}$ frequency vaginal probe for improved resolution. Sections were taken in serial, longitudinal and transverse manner. Masses, if identified, were localized and defined, internal architecture were analyzed. On TVS following findings were noticed to assess the presence or absence of ectopic pregnancy like empty uterine cavity. with one of the following adnexal regions findings:

- an inhomogeneous mass or blob sign adjacent to ovary
- a mass with hyper-echoic ring around the gestational sac or bagel sign

- A gestational sac with a fetal pole with or without cardiac activity.

We recorded all these findings on a pre-designed proforma.

We used SPSS version 14 for statistical analysis of the data. The demographic variable like age was recorded as simple descriptive statistics giving mean and standard deviation. Frequency and percentage was presented for un-ruptured ectopic pregnancy.

\section{Results}

All patients fulfilling the inclusion / exclusion criteria were enrolled to determine the frequency of unruptured ectopic pregnancy in a tertiary care hospital of Hail City, Saudi Arabia.

In our study, $64.67 \%(n=97)$ of the cases were between $15-30$ years of age while $35.33 \%(n=53)$ were between $31-44$ years, mean \pm sd was calculated as $26.34 \pm 2.67$ years. (Table 1) frequency of unruptured ectopic pregnancy was recorded in $14 \%$ of the cases (Table 2).

Table 1: Age Distribution $(\mathrm{n}=150)$.

\begin{tabular}{||c||c|c|}
\hline Age in Years & No. of Cases & Percentage \\
\hline \hline $15-30$ & 97 & 64.67 \\
\hline \hline $31-44$ & 53 & 35.33 \\
\hline \hline Total & 150 & 100 \\
\hline \hline Mean \pm SD & \multicolumn{2}{|c|}{$26.34 \pm 2.67$} \\
\hline
\end{tabular}

Table 2: Frequency of Unruptured Ectopic Pregnancy $(\mathrm{n}=$ 150).

\begin{tabular}{||l||c||c||}
\hline Un-ruptured & No. of cases & Percentage \\
\hline \hline Yes & 21 & 14 \\
\hline \hline No & 129 & 86 \\
\hline Total & 150 & 100 \\
\hline
\end{tabular}

\section{Discussion}

Pregnancy related deaths are significantly higher in 
women with ectopic pregnancy in first trimester. Authors are of the view that early detection and management of this morbidity may reduce the maternal mortality. ${ }^{11}$

In our study we evaluated the frequency of unruptured ectopic pregnancy in patients coming to our hospital.

A significant proportion of our patients was recorded between 15 - 30 years of age, similarly to Majhi AK and colleagues.

Diagnosis of un-ruptured ectopic pregnancies in developed countries ranges from $88 \%$ to $100 \% .^{12-14}$ However, the frequency of unruptured ectopic pregnancy during past 3 decades was recorded between $1.1 \%$ to $8.5 \%$ of the cases. ${ }^{15}$

Khaleeque $\mathrm{F}$ and colleagues ${ }^{16}$ conducted a study at Karachi analyzed the risk factors and assessed the results of management with respect to maternal morbidity and mortality of ectopic pregnancy during the last three years and found un-ruptured cases of ectopic pregnancy in 6 out 39 i.e. (15.38\%), these findings are consistent with our results.

Trans-vaginal sonography is helpful for identifying the site of pregnancy and ectopic pregnancy before its rupture. This modality is highly reliabale. ${ }^{17}$ Conservative management of the disease is associated with life - threatening risk. Two RCTs are found who managed these patients conservatively. ${ }^{18-19}$ Egarter et al. $(1991)^{18}$ compared conservative management and local and systemic prostaglandins including 23 women with an unruptured ectopic pregnancy and a serum betahCG concentration was recorded $<2,500 \mathrm{mIU} / \mathrm{ml}$. This study revealed that conservative management was significantly lower chances of success than prostaglandin therapy.

In cases with stable hemodynamic and no fetal cardiac activity on TVS, use of methotraxate may be an effective treatment. ${ }^{20}$ A single - dose $\left(50 \mathrm{mg} / \mathrm{m}^{2}\right)$ or multiple-doses ( $1 \mathrm{mg} / \mathrm{kg} /$ day) of methotraxate may be used. In women administered with multiple - dose treatment, the maximum dose is repeated four times until the b-hCG level is decreased $>15 \% .^{20}$ In this method of treatment, the b-hCG level are checked with 48 - hour intervals, and on the days without MTX, the patient is administered leucovorin with a dose of 0.1 $\mathrm{mg} / \mathrm{kg} /$ day. $^{21}$ If the MTX is failed to reduce b-hCG level by the fourth dose, surgery should be preferred. Hemodynamic stability of the patients should be monitored carefully during medical treatment.

We are of the view that early use of transvaginal ultrasonography may enable us to detect un-ruptured ectopic pregnancy and these patients may be managed with medical treatment.

\section{References}

1. Aziz S, Wafi BA, Swadi HA. Frequency of Ectopic Pregnancy in a Medical Centre, Kingdom of Saudi Arabia. JPMA, 2011; 61: 221.

2. Ayaz A, Emam S, Farooq MU. Clinical course of ectopic pregnancy: A single - center experience. J Hum Reprod Sci. 2015; 6: 70-3.

3. Al-Turki HA. "Ectopic pregnancy: prevalence and risk factors in Saudi Arabian Women," Saudi Medical Journals, 2012; 339: 179-82.

4. Centers for Disease Control and Prevention (CDC), "Ectopic pregnancy — United States, 1990 - 1992," MMWR Morbidity and Mortality Weekly Report, 1995; 44: 46-8.

5. Shah N, Khan NH. Ectopic pregnancy: presentation and risk factors. J Coll Physicians Surg Pak. 2005; 15: 5358 .

6. Kazandi M, Turan V. Ectopic pregnancy; risk factors and comparison of intervention success rates in tubal ectopic pregnancy. Clin Exp Obstet Gynecol. 2011; 38: 67-70.

7. Tasnim N, Mahmud G. Advance abdominal pregnancya diagnostic and management dilemma. J Coll Physicians Surg Pak. 2005; 15: 493-5.

8. Kdous M. Non surgical management of ectopic - pregnancy. Tunis Me. 2006; 84: 331-9.

9. Condous G. Ectopic pregnancy — risk factors and diagnosis. Aust Fam Physician, 2006; 35: 854-7.

10. Monga A, editor. Gynacology by ten teachers. London: Hodder Arnold; 2006: 89-102.

11. Barnhart KT, Sammel MD, Gracia CR. Risk factors for ectopic pregnancy in women with symptomatic first trimester pregnancies. Fert Steril, 2006; 20: 1.

12. Bruce GC, Walace CN, Lisa AK, Jame DK, Robin I. Vaginal sonographic findings and HCG dynamics of early intra uterine and tubal pregnancy. Obstet Gynecol. 1990; 75: 423-427.

13. Ander DS, Ward KR. Medical management of ectopic pregnancy-the role of methotrexate. $\mathrm{J}$ of Emerg Med. 1997; 15: 177-182.

14. Dimitry ES, Atalla RK. Modern lines of management of ectopic pregnancy. Br J of Clin Pract. 1996; 50: 376380 .

15. Obed SA, Wilson JB, Elkins TE. Diagnosing unruptured ectopic pregnancy. Int J Gynecol Obstet. 1994; 45: 21-25.

16. Khaleeque F, Siddiqui RI, Jafarey SN. Ectopic Pregnancies: a Three Year Study. J Pak Med Assoc. 2001; 51: 240 .

17. Condous G, Okaro E, Khalid A, Lu C, Van Huffel S, Timmerman D, et al. The accuracy of transvaginal 
ultrasonography for the diagnosis of ectopic pregnancy prior to surgery. Hum. Reprod. 2005; 20 (5): p. 1404-9.

18. EgarterC, Kiss $\mathrm{H}$ and Husslein P. Prostaglandin versus expect ant management in early tubal pregnancy. Prostaglandins Leukot Essent Fatty Acids, 1991; 42: 177179.

19. Korhonen J, Stenman U and Ylostalo P. Low dose oral methotrexate with expect ant management of ectopic pregnancy. Obstet Gynecol. 1996; 88: 775-8.

20. Mukul LV, Teal SB. Current management of ectopic pregnancy. Obstet Gynecol Clin North Am. 2007; 34: 403-19.

21. Bangsgaard N, Lund CO, Ottesen B, Nilas L. Improved fertility following conservative surgical treatment of ectopic pregnancy. BJOG, 2003; 110: 765-70. 